\title{
LA BIOGRAFÍA, ENTRE EL VALOR EJEMPLAR Y LA EXPERIENCIA VIVIDA
}

\author{
Elena Hernández Sandoica
}

Universidad Complutense de Madrid

\section{RESUMEN}

El artículo revisa los usos tradicionales de la biografía, y los inscribe en el contexto de las corrientes historiográficas de actualidad. Explora sus posibilidades y apuesta por una interpretación en la que su reciente éxito gira en torno al rescate fundamental del concepto de «experiencia».

PALABRAS CLAVE: Biografía, historiografía, nuevas corrientes, experiencia vivida.

\section{SUMMARY}

This paper reviews traditional uses of biography, inserting them into historiographical new trends. Also explores their possibilities and argues for an interpretation going around the concept of «experience».

KEY WORDS: Biography, historiography, new frends, lived experience.

La biografia atraviesa actualmente lo que para algunos resulta ser una inesperada etapa de éxito y prosperidad. Su cultivo, no obstante, se acostumbra de antiguo en los países de habla inglesa, donde la base fuertemente individualista, - culturalmente liberal - del gusto por el pasado explica, y justifica, ese cultivo y aprecio constantes.

En cualquier otro lugar, por el contrario, los relatos biográficos, las memorias, diarios, recuerdos y autobiografias gozaron hasta aquí de desigual fortuna. De manera que no puede considerarse siempre tan clara, al menos en ciertos casos bien conocidos, esa íntima adscripción a la «modernidad» y a sus usos literarios que, con toda razón, se atribuye en principio a la escritura de base experiencial y a los relatos de autorreflexión ${ }^{1}$.

1 Burdiel, I. (2000), «La dama de blanco», en Burdiel, I. y Pérez Ledesma, M. (coords.) Liberales, agitadores y conspiradores, Madrid, Espasa, pp. 17-47. 
Procedente de horizontes e inspiraciones diversos, la biografía halla su origen ya en la antigüedad en el subgénero de la vida ejemplar, con un núcleo de intereses y de motivaciones fuertemente político, incluso partidista, y a la busca de unos rasgos constantes dignos de emulación. Al margen de ello, resulta difícil fijar con precisión cuál sea el arranque del interés extenso por conocer las vidas — aquí en plural, por su enigmática diversidad - de pintores y escritores, los primeros objeto de curiosidad desde el Renacimiento, y cuyas peripecias exasperan el riesgo y la aventura; los segundos, más cerca en cambio de las inquietudes que despierta el Romanticismo y su arriesgada apuesta por traer al primer plano la subjetividad.

Más recientemente, en disciplinas o historias sectoriales que desde el positivismo sistematizamos como historia de la filosofia e historia de la ciencia, las biografías hallaron siempre espacio reservado. Las dos materias - ciencia y filosofía - gustan de sostener, desde el principio, una fuerte tradición explicativa que se anudó narrando, una tras otra, las vidas de quienes las irían creando, entre trayectorias intelectuales y experiencias biográficas.

De cualquier modo, si bien se mira, ésta resulta ser una estrategia discursiva tampoco desprovista de carga moral y proyección educativa, por más que en cada uno de los ámbitos disciplinares obedezca a circunstancias asimétricas. Disociar la trayectoria biográfica del filósofo de su sistema propio, de sus ideas y su pensamiento, si no prácticamente imposible, sí por lo menos resulta más difícil que disociar el descubrimiento científico de su descubridor, de su visión del mundo y de las vivencias y emociones que los científicos experimentasen. Por eso precisamente es a la historia de la ciencia (y en consecuencia al modo de guiar su conducta los científicos) a la que, tentativamente convertida en una especie de tradición humanista, se inviste en las sociedades contemporáneas de mayor valor formativo, de un uso directamente instrumental y ejemplar ${ }^{2}$.

\section{VIDAS EJEMPLARES}

«Parvis componere magna»

(Virgilio: Bucólicas)

Desde este ángulo sociocultural, la biografía es un género por definición edificante y moralizador, al servicio de una estrategia de socialización desti-

2 CARr, H.W. (1929), Leibniz, Boston, Little Brown, p. 203. 
nada a colectivos amplios. Y a la par, desde el punto de vista de la proyección individual, resultaría ser un importante instrumento en la creación cultural del «yo», un hito decisivo en la aparición del sujeto moderno en Occidente, así como una fuente constante de su multiplicación ${ }^{3}$.

Sea como fuere, tanto filósofos como científicos de todo tipo han merecido páginas abundantes que muestran a la posteridad sus vidas y experiencias, tratándose no sólo de fijarlas en el recuerdo, sino también de convertirlas en fuente unas veces de mímesis y otras de creación e innovación. Sobre todo en el caso de los hombres de ciencia -recientemente también de las mujeres científicas, o especialmente dadas al cultivo del conocimiento y la educación ${ }^{4}$-, sobre la trama de aquellas mismas vidas se construyen modelos, patrones que se ofrecen a los lectores como guías a seguir. De manera evidente en los medios culturales de origen o influencia protestante, tal género de biografías llevaría implícito un sistema completo de valores formativos (no es el menor aquel de la perseverancia), un catálogo de virtudes que define e informa la ambición del carácter, su forja controlada desde la infancia y hacia la juventud.

La educación del niño, y más aún del joven, contiene en la panoplia de vidas ejemplares, con rasgos bien definidos, el afán del esfuerzo personal y su casi segura recompensa con merecidos logros y el reconocimiento general. Pero también acaso podrá leerse allí, en esos textos de final feliz, introducida al modo de un juego decisivo, la presencia de cuanto acaece en nuestras vidas inesperadamente, la trascendente irrupción del azar.

Una presencia, ésta del azar, que se hará positiva, tan solo si al lector se le brinda como premio al esfuerzo. El hallazgo científico casual, cuando menos se espera o buscando otra cosa («serendipia»), viene a ser ciertamente una inyección de aliento para orientar la acción en lo indeterminado, una especie de taller de experiencias contra el desánimo o un horizonte útil de expectativas contra el corsé opresivo de la fatalidad. En uno y otro caso - hoy lo mismo que ayer-, la historia de esas vidas que adorna un relato e inculca una moral sigue siendo inmensamente popular, sobre todo si — como nos

3 SöDERQVIST, T. (1996), «Existential projects and existential choice in science: science biography as an edifying genre», en ShorTLAnd, M. and Yeo, R. (eds.) Telling Lives in Science. Essays on Scientific Biography, Cambridge, Cambridge U. Press, pp. 45-84: «Such life stories not only provide us with opportunities to understand ourselves, intellectually as well as emotionally, but may also change and create ourselves.» (cit. p. 47).

4 Una muestra cabal en BABINI, V.P. y LAMA, L. (2000), Una «donna nuova». Il feminismo scientifico di Maria Montessori, Milán, Franco Angeli. 
recuerda Barraclough- «esta moral es la que la mayoría de la sociedad desea escuchar» ${ }^{5}$.

Pero lo cierto es que, incluso allí donde las biografías habían prosperado usualmente, donde constituían una grata costumbre editorial, se vieron relegadas y oscurecidas hace unas cuantas décadas (cuarenta o cincuenta años), frente a otros modos de escribir la historia. Eran los tiempos - no demasiado largos, pero sí de un fulminante impacto y rápida expansión - en que predominara la tentación holística, cuando imperó la inspiración estructural y/o cuantitativa, de cuyo ocaso reciente se ha escrito mucho ya ${ }^{6}$.

Desde el último tercio del siglo XX, prosperando hasta hoy, es perceptible en cambio un nuevo avance del interés por lo biográfico ${ }^{7}$, sin que exista excepción a esta tendencia en medios historiográficos antes poco ligados al historicismo, como es el nuestro propio. (Inscrito a su vez en un sucedáneo de tradiciones de escuela que, con frecuencia, han sido reconocidas como muy poco dadas al cultivo del género, aunque este tópico pueda ser - iy cómo no! - tan discutible como la mayoría). En cualquier caso, parece perfilarse también aquí, en nuestro medio propio, junto a la expansión de la categoría de identidad que portan las biografías llamadas «colectivas» (también llamada prosopografia), el empleo afanoso, más o menos logrado, de la biografía individual. También trufado de inspiraciones nuevas, como los feminismos, en cuyo núcleo se organiza disperso un rosario de biografías de mujeres, diversas entre sí ${ }^{8}$.

Considerada como un subgénero popular en su conjunto, la biografía resulta un tipo de relato histórico con frecuencia apreciado por los lectores de historia no profesionales, atraídos por sus «relatos» y secuencias, por las peripecias vitales que los arman y nutren. En general, es ciertamente del agrado

5 Barraclough, G. (1979), Historia. En corrientes de la investigación en Ciencias sociales, vol. 2, Madrid, Tecnos/Unesco, 1981.

6 Un buen resumen en IGGERS, G.G. (1998), La ciencia histórica en el siglo XX. Las tendencias actuales, Barcelona, Idea Books. Por mi parte, véase HERnÁndEZ SANDOICA, E. (1995), Los caminos de la historia. Cuestiones de historiografía y método, Madrid, Síntesis y (2004), Tendencias historiográficas actuales. Escribir historia hoy, Madrid, Akal.

7 Por ejemplo Morales, A. (1987), «En torno al auge de la biografía», Revista de Occidente (julio-agosto); o «Biografía y narración en la historiografía actual», en VV.AA. (1993), Problemas actuales de la historia, Salamanca, Universidad de Salamanca, pp. 229-257.

8 Una muestra reciente, en nuestra historiografía, en CAPEL, R. (coord.) (2004), Mujeres para la Historia. Figuras destacadas del primer feminismo, Madrid, Abada editores. (Con textos de M. Vincent-Cassy, M. Bolufer, B. Taylor, E. Bloch-Dano, J. Howarth, G. Scanlon e I. Alberdi). 
de un variado público culto — «científicos» incluidos-, poseedor de una difusa curiosidad humanística.

Pero frente a esta realidad lectora que es casi una constante, pues persiste sin grandes cambios desde bien antiguo (y que permite subsistir a «biógrafos» de muy distinta estirpe y calidad literarias), cabe ahora subrayar, como una indiscutible novedad, el incremento del valor objetivo que alcanzan hoy las biografías como ejercicio profesional para los historiadores de oficio, como si fuera un reto o una tendencia más. Ahí enlaza también, en consecuencia, su reciente consumo como «nuevo» producto historiográfico, relacionado en parte con su elección como objeto legítimo de prospección por un mayor número de historiadores cada día, y algunos de ellos muy relevantes además.

\section{EL RETORNO DE LO BIOGRÁFICO}

«Todos los observadores de la vida de los pueblos conocen esos giros 'de vuelta' de las ruedas siempre en movimiento de la historia»

(I.S. Turgéniev: Recuerdos de Belinski).

La biografía «clásica» por excelencia, la que va acumulando y sumando, una tras otra, un puñado de trayectorias biográficas que se estiman «notables» y «significativas», es cada vez más apreciada por públicos extensos y variados, independientemente de su interés científico. Una circunstancia que tiene seguramente que ver con el auge del interés por «lo privado» y «lo individual», lo propio y subjetivo, lo particular como un elemento identitario consciente. Y que es un interés que, siendo en modo alguno inesperado en la historiografía, se ha hecho también presente en el contexto general de las ciencias sociales. (Y ahí sí que reside la novedad, sin duda),

En efecto, es en sociología y en antropología donde las historias o relatos de vida llevan tiempo jugando un papel fundamental ${ }^{9}$, inscritos en el marco de estrategias teóricas cualitativas que no son nuevas, pero que se han extendido y renovado mucho - haciéndose cada día más sofisticadas-, y que suelen ser llevados a la práctica con fundamentos metodológicos (el método humanista) que se declaran «micro», como a su vez propondrá la microhistoria ${ }^{10}$.

9 Bertaux, D. (1981), Biography and Society: The Life History Approach in the Social Sciences, Beverly Hills, Sage.

10 LeVI, G. (1989), «Les usages de la biographie», Annales 6, pp. 1325-1336. 
De tal modo y manera que el hablar, en este punto y hora, de las técnicas a que obliga al oficio el cultivo de biografías, o inventariar las consecuencias epistemológicas de su «vuelta» al taller de los historiadores, además de constituir prácticamente un lugar común a la hora de discutir las corrientes y flujos que inspiran las recientes escuelas y subgéneros, es ante todo una ocasión para reflexionar acerca del tipo de conocimiento que implica y nos ofrece la historia. El despliegue reciente de los «estudios de género» ha introducido complejidad en este cometido, no ya tanto porque supone indudablemente un valor añadido de información y análisis, como porque desvelar la vida de algunas mujeres rescatándolas de un segundo plano o de la oscuridad, nos plantea de paso la pregunta teórica (política, por ende) de cuáles son los porqués de esa invisibilidad.

La frecuencia y el ritmo de la aparición de biografías han aumentado en los últimos tiempos, aquí y allá. De manera que ya casi no sorprende el hecho de que, donde vean la luz las «nuevas» biografías - prácticamente con independencia de cuáles sean sus protagonistas, si hombre o mujer, antiguos o modernos-, los títulos más favorecidos por la publicidad y la crítica historiográfica pasen a ser best-sellers, aspirantes a «clásicos» que figuran entre los más vendidos.

A la floración tradicional de biografías (artistas y científicos, filósofos y novelistas, reyes y personajes en el límite de lo hagiográfico: las tradicionales vidas de santos), hay que añadir el incremento de las biografías de políticos y personajes públicos de diverso interés, un caudal emergido aún no hace tanto y que constituye un tipo de escritura cercano a la novela en más de una ocasión, cuando no está situado al borde mismo de la literatura de ficción. De hecho, como suele advertirse por sus detractores, el público lector de unos y otros textos suele ser casi el mismo, los alterna y combina. Y a pesar del reclamo editorial que en las contraportadas o reseñas busca frecuentemente fijar los límites entre «literatura» y «verdad» (verdad histórica), tal tipo de construcción retórica muestra a las claras labilidad.

Pero atención: Se da la paradoja actualmente de que no siempre la vida que se narra resulta ya ejemplar - al menos en el sentido antiguo de la expresión-, y acaso ni siquiera parezca interesante en una forma clara, convencional, del término ${ }^{11}$. ¿Qué ocurre entonces, para que encuentre una cierta

11 El escritor Félix de Azúa, a propósito de esta expandida curiosidad reciente, lo expresa así: «Lo singular es que muchos de estos escritores, si no todos, llevaron vidas vulgares, monótonas, aburridas, a veces miserables. Se entiende la pasión que puede inspirar una biografia de Trotsky, de Garibaldi, del coronel Lawrence (...) Todos ellos vivieron episodios 
explicación verosímil la aparición de esa curiosidad inesperada por lo biográfico y lo personal...? Sería como si una especie de «edad dorada de la biografía» - con el aplauso de unos pocos profesionales de la historia al principio, pero después con el consentimiento alegre de los más - viniera a desplegarse desde hace un par de décadas, a raíz de los años 80 del siglo $\mathrm{XX}^{12}$.

Con su apertura se cierra en fin, siquiera provisionalmente, aquella ausencia de «los más», aquel olvido de los nombres comunes cuya recuperación reclamaba, desde la década de 1920, la historia social, iniciándose así la reparación a la ignorancia de tantas vidas, de tantas experiencias del pasado. Restaurar la memoria, ofrecer un rescate del olvido generalizado, reinicia de este modo el papel de las ciencias sociales, replanteándose su función y estrategias; pero también, de paso, reestablece la vieja relación entre «historia» y «memoria» como una especie de palimpsesto desenvuelto hacia atrás.

A esta situación nueva que ha venido a forjarse en los últimos tiempos, le convendría aquello que escribió el norteamericano Henry James en 1884, refiriéndose al ruso Turguéniev: «El propósito profundo que empapaba todos sus trabajos era mostrar la vida misma. El germen de la historia, en su caso, no era nunca un argumento o un tema - eso era lo último en que pensaba-, sino la representación de ciertas personas. Todo se le aparecía por primera vez en forma de un individuo o combinación de individuos, a los que deseaba ver en movimiento, pues estaba seguro de que esa gente debía hacer algo especial o interesante. Estaban ante él, vivaces, definidos, y él deseaba mostrar todo lo que fuera posible de su naturaleza» ${ }^{13}$.

De una tensión pareja vive sin duda, a estas alturas, esa ficción biográfica que ha venido a colmar una parte creciente del nuevo gusto extenso por las biografías, aquel que anima a los novelistas a construir el relato real. Y de ese mismo aliento se deriva a su vez, un cierto modo de recuperación del género biográfico en la historiografía. Podría suscribirse - ahora más que quizá en el momento mismo en que fue formulada, hace más de una década - la intuición del inglés Peter Burke cuando afirmó que, en el caso hipotético de que se encuentre en marcha un cierto tipo de consenso nuevo para la discipli-

curiosos, aventuras famosas, experiencias perversas o magnificas, dignas de nuestra consideración, pero ¿y Josep Pla, por ejemplo?» («De los famosos hombres antiguos», El País, jueves 9 de diciembre de 2004, p. 13).

12 Bowker, G. (1993, 8 enero), «The age of biography is upon us», Times Higher Education Supplement.

13 En The Atlantic Monthly, enero 1884, citado en I.S. Turguéniev (2000): Páginas autobiográficas, Madrid, Alba editorial. Introducción de V. Gallego Ballestero, pp. 17-18. 
na, éste atravesaría por la psicología colectiva. Porque ésta nos llevaría a «vincular los debates sobre la motivación consciente e inconsciente con los de las explicaciones sobre lo individual y lo colectivo» ${ }^{14}$.

No obstante, fue la psicología individual la que antes hubiera de atraer a los historiadores, la que antes recabó su atención - continua o discontinua-, y la que antes mereció sus objeciones, también. La explicación psicológica era uno de los recursos tópicos de la historiografía, como es sabido, desde bien al principio. Aunque, si bien se había acomodado con cierta facilidad a los desarrollos más primitivos de la psicología como ciencia, la irrupción del psicoanálisis la perturbó ${ }^{15}$, y le supuso un reto.

Porque para Freud y sus seguidores - no descubrimos nada al decir esto-, el ser humano está dotado de una complejidad espiritual en la que el consciente es solo una parte pequeña. Desconociendo como desconocemos la multitud de procesos subconscientes que forman nuestro pensamiento, incluso los deseos y los sentimientos que en él se originan, es difícil analizarlos de modo unitario e independiente. Se nos ofrecen como manifestaciones inestables, producidas por prolijos entrecruzamientos de estructuras en las que se contienen no solo los deseos reprimidos, los miedos y las fobias, sino también una serie de factores sociales, ideológicos y políticos, de los que tampoco somos conscientes en realidad. El Yo nace de ahí, del cruce de esas estructuras en perpetuo conflicto, que son contradictorias inevitablemente. La biografía ha sido, según esta rejilla de factura freudiana, un terreno abonado para la interpretación psicoanalítica (o si se prefiere, el derivado psicohistoria), para la aplicación de las teorías o enfoques del psicoanálisis como herramienta principal o, por el contrario, su respaldo como referente vago y general ${ }^{16}$.

Recientemente ha vuelto a divulgarse un esquema de este tipo por mediación de la historia oral, impuesto de la mano amistosa de la historia de vida. Son las suyas opciones de análisis de una diversidad compleja, que tienen en la sociología y en la antropología sus respectivas tradiciones metodológicas y que, alumbrándolas con la nueva luz que proporcionan las teorías psicológi-

14 Burke, P. (1991), «Obertura: la nueva historia, su pasado y su futuro», en P. Burke, ed. Formas de hacer historia, Madrid, Alianza editorial, p. 34.

15 Por ejemplo, Mazlish, B. (ed.) (1963), Psychoanalysis and History, Londres, Prentice Hall; o D. LA CAPRA (1989), «History and Psychoanalysis», en Soundings in Critical Theory, Ithaca \& Londres, Cornell University Press.

16 Röcklein, H. (ed.) (1993), Biographie als Geschichte, Tubinga, Edition Diskord. Y allí, A. Levallois, «Biographie, Psychohistoire und Psychoanalyse. Der Stand der Forschung in Frankreich», pp. 39-62. 
cas y lingüísticas, las recrean a su vez de continuo. Entendiendo la «historia de vida», a la manera del francés Pierre Bourdieu, como el resultado de un doble esfuerzo (esfuerzo del narrador y esfuerzo del biografiado) por otorgar sentido a una existencia y por darle un significado conveniente y plausible a la experiencia individual ${ }^{17}$, hay que tener en cuenta - como a su vez subraya Ives Clot - que «el acto humano no se produce en línea recta, sino por encrucijadas, y según círculos cuya mayor parte es descentrada socialmente» ${ }^{18}$.

El impulso autobiográfico comienza así, en este punto mismo, como un intento de fijar el carácter fugitivo, eternamente inestable, de la experiencia humana, y en esa labilidad consustancial lleva por tanto implícita la contradicción, incluso para algunos su «desfiguramiento» ${ }^{19}$.

La dificultad evidente de tender puentes entre la psicología individual y la colectiva no es un problema que haya pasado desapercibido a los historiadores, lo mismo que no es ajena su consideración - como núcleo constituyente del ámbito de relaciones entre lo general y lo particular - a los científicos sociales, vistos en su conjunto. A veces resulta sin embargo, como advirtió Ralf Dahrendorf, que «se tiende a convertir el psicoanálisis en una metáfora imprecisa de la sociología» ${ }^{20}$. Pero más censurable es, con todo, la tentación de introducir en el relato, usos vulgares de conceptos psicoanalíticos como «complejo de inferioridad», «represión», «subconsciente» o «introversión», por citar los más frecuentes tópicos, ajenos a su marco teórico y tantas veces aplicados sin rigor.

Para un psicohistoriador refinado como es Alain Besançon, resulta «un ejercicio intelectual inútil y dudoso el tratar de descubrir conceptos psicoanalíticos dentro del material histórico». Al contrario, lo pertinente es «considerar el material desde el punto de vista psicoanalítico y entonces sacar a la luz relaciones entre hechos que parecían accidentales o a los que previamente no se les había dado la categoría de hechos» ${ }^{21}$. Muchos de los biógrafos más recientes de figuras que ya habían sido antes reiteradamente biografiadas, se han decidido ahora — una vez ya garantizado el éxito - a operar así.

17 Bourdieu, P. (1986), «L'illusion biographique», Actes de la Recherche en Sciences Sociales 62/63, pp. 69-72.

18 ClOT, I. (1989), «La otra ilusión biográfica», Historia y fuente oral 2, pp. 35-39.

19 DE MAN, P. (1979), «Autobiography as De-facement», Modern Language Notes 94, pp. 919-930.

20 Dahrendorf, R. (1968), Society and Democracy in Germany, Londres, Weidenfeld, p. 375 .

21 BeSANÇON, A. (1968), «Psychoanalysis: auxiliary science or historical method?», Journal of Contemporary History III/2, p. 152. 
Sin embargo, todo historiador de tipo tradicional —o que simplemente guste de frecuentar a los clásicos, sobre todo Tucídides - cree que los instrumentos que posee su oficio (su modo de entender la realidad y procesar sus huellas) le permiten saber sobre la naturaleza humana cosas que, de otro modo, posiblemente, no llegaría nunca a conocer. Y con frecuencia admira la sabia manera en que, en los albores del teatro moderno, Shakespeare supo fundir psicología e historia para ofrecernos las muestras más profundas y sutiles, las más extraordinarias y sensibles, de una idéntica percepción. En pautas como éstas, articuladas de modo preferente en la elección biográfica, va a residir la base cognitiva, de maneras específicamente occidentales, que encierra nuestra tradición profesional historicista, referida a los seres humanos y sus claves interpretativas. Al fin y al cabo, tal es el horizonte de toda interpretación no cíclica del tiempo que tenga por objetivo añadir lucidez a la conciencia sobre la naturaleza humana.

Muchos historiadores se han contemplado a sí mismos, sea cual sea la época, desde este ángulo, y lo han hecho con toda normalidad, como si fuesen psicólogos de pleno derecho. Debe reconocerse que en la intuición se basan ciertamente - es decir, nos basamos- los historiadores, casi con absoluta prioridad, para juzgar (mediante conjeturas bien fundadas, mejor cuanto más verosímiles parezcan) las acciones de unos y de otros, sea cual sea el tiempo y el lugar. En Dilthey, sin embargo, se condensa el modelo más usado en la historiografía para ligar el conocimiento de la historia a la introspección, para unir el saber sobre uno mismo al estudio de la conducta de los otros.

Si es cierto que, como escribió hace poco la feminista Elaine Showalter, las biografías aún conservan su fuerza cuando se desvanece la teoría ${ }^{22}$, pudiera ser también que el vacío dejado por los enfoques teóricos fuertes, viniera hoy a llenarse con un retorno más denso y mucho más antiguo, el del historicismo en su forma más pura de idealismo psicologizante, al modo en que Dilthey lo sistematizó en su configuración particularista de las ciencias del espíritu: «Hay una sola sociedad - volvía a escribirse a principios de los años 90 del siglo XX - , que cada individuo construye para sí mismo, o sí misma... Cada persona entonces, al menos en parte, vive en una sociedad diferente $»^{23}$. Palabras como éstas son un eco de Dilthey, quien vió a la biografía y la autobiografía respectivamente como principio y fin de las ciencias humanas. Más

22 SHOWALTER, E. (2002), Mujeres rebeldes. Una reivindicación de la herencia intelectual feminista, Madrid, Espasa, p. 17. [Más propio el título en inglés: Inventing Herself, N. York, 2001].

23 Williams, L.P. (1991), «The life of science and scientific lives», Physics 28, pp. 199-213. 
literariamente incluso, Carlyle había creído que la historia estaba constituida por «la esencia de innumerables biografías».

En esta misma estela se sitúa — a pesar de su aparente radical novedad-, la sugestiva propuesta del italiano Carlo Ginzburg a finales de la década de 1970, con independencia de que entonces pudieran sorprendernos a la mayoría tanto su aparición, contra todo pronóstico, como su inusual elegancia retórica y, aun más, su esquemática sofisticación. Con todo, no exageran quienes piensan, sopesando los fallidos trabajos de más de un psicohistoriador, que «la mayoría de los esfuerzos para casar a la psicología con la historia han acabado en divorcio o directamente en canibalismo» ${ }^{24}$.

Pero esto no será - conviene recordarlo - por una falta de interés de los historiadores en abordar la psique del individuo y sus problemas, o por pereza o descuido en ahondar en el peso de las incidencias del carácter personal en la vida política, o incluso por desidia en tratar de fijar fronteras y caminos entre lo propiamente rutinario de la existencia humana y lo ligado, en cambio, a la intervención única, a decisiones o determinaciones que conllevan de hecho ruptura o «excepción». Muy al contrario han sido ésas, tradicionalmente, las empresas más gratas a los historiadores.

No obstante, la forma de acercamiento entre aquellas dos disciplinas ( $p s i$ cología e historia) que más huella ha dejado en la historiografía tiene que ver con una idea fuerte, o principio esencial, que a lo largo del siglo XX ha inspirado muchas - y en su mayoría buenas - páginas de la llamada historia de las mentalidades o, en términos más amplios y más actualizados, la que se llama ahora historia sociocultural. Muestran en su conjunto, de forma inconfundible, un intento (ya sea espontáneo o ya sistemático) de conciliar al hombre con el medio, de interpretar el individuo en su contexto, de imbricar en una red de relaciones lo particular y lo general.

En la historiografía posterior a la II Guerra mundial fue produciéndose una progresiva sensibilización hacia el cruce entre ambos polos, una tendencia esporádica al principio o accidental, que enseguida se volvería usual. En el fondo, parecía una incipiente reacción contra el exceso de racionalidad en los análisis, contra el olvido de lo irracional y lo inconsciente en unos textos de historia escritos de tal modo que, muchas veces, no parecían tales - puesto que hablaban más de los procesos que de los seres humanos, los cuales quedaban desplazados del argumento como sujetos-. Quienes parten de elemen-

24 Keniston, K. «Psychological Development and Historical Change», en TH.K. RABB y RotberG, R.I. (eds.) (1971), The Family in History. Interdisciplinary Essays, N. York, Harper \& Row, pp. 141-157, cit. p. 141. 
tos de tipo psicológico en un discurso en cambio socio-científico, y sitúan esos elementos en pleno centro de su «interpretación», consideran que la psicología humana no es una constante inalterable y universal, y que por lo tanto no constituye una base «fija» para interpretar, con cierto margen de seguridad, la actividad humana. Por el contrario la conciben como un aspecto básico de toda situación social, como un dato inexcusable a someter a aquella «explicación» que, de manera ajustada, solo nos proporciona cada particular contexto histórico.

El inglés Geoffrey Barraclough, a la altura de 1979, lo presentaba con sencillez así: «Ningún historiador que se dedique a temas como el imperialismo, el nacionalismo o el totalitarismo puede ignorar sus raíces psicológicas, y todo historiador, sea cual sea la sociedad y la época que esté tratando, debe tener en cuenta las tensiones psicológicas, las tensiones entre las fuerzas de la estabilidad y las fuerzas del cambio, pero especialmente la ineludible tensión que opera en todo momento entre la superestructura racional del orden social, necesaria para asegurar el funcionamiento continuado de la sociedad y las reacciones instintivas en masa de sus miembros, que son el tejido y la sustancia de la historia» ${ }^{25}$.

\section{EXPERIENCIA VIVIDA Y TEORÍAS SOCIO-CIENTÍFICAS}

"Cuando las teorias se desvanecen, las biografias aun conservan su fuerza»

(Elaine Showalter: Mujeres rebeldes).

Han sido muchas, y muy ramificadas, las influencias de la psicología social en la organización del campo denominado «historia de las mentalidades», como hemos venido adelantando. Podría traerse también a colación, para este ejercicio combinado de reflejos recíprocos, el esfuerzo de alguien como el sociólogo alemán Norbert Elias, ya en la fecha de 1936, por codificar un cuerpo de doctrina sociológico en una dirección muy similar, con sugerencias bien aprovechadas, en estas últimas décadas, por los historiadores france$\operatorname{ses}^{26}$. Pero igualmente conviene no olvidar que, tanto en la demografia histórica como en la historia de la familia de enfoque cualitativo (aunque no sólo

25 G. BarRaclough (1979), Historia cit., p. 379.

26 Elias, N. (1987), El proceso de la civilización. Investigaciones sociogenéticas y psicogenéticas, México, FCE. [La edición en alemán, en 2 vols., 1977 y 1979]. 
desde luego en ellas), muchos estudios sobre la infancia, la ilegitimidad, el matrimonio o la sexualidad vienen marcados por un fuerte interés - difuso o diluido, si no ortodoxo- de carácter psicologista, y que antes o después derivarán hacia la biografía individual ${ }^{27}$.

Pero en ámbitos de subespecialización como aquéllos, si bien durante un tiempo nadie osaría negar «que el individuo sea libre para escoger entre ciertas posibilidades de acción», solía insistirse en cambio en que dicha libertad de acción vendría fuertemente condicionada tanto por circunstancias externas concretas como por valores y actitudes profundamente arraigadas, «no colocadas al azar», sino - por el contrario - «interdependientes, adaptadas a un modelo y sujetas a variaciones recíprocas». A los ojos de la mayoría, una vez aprendidas las lecciones teóricas de la sociología y la psicología social, parecería un reblandecimiento, una elección banal, el volver sobre los componentes de la acción individual, y se trataba de evitar el riesgo de caer en la trivialidad sobre la toma de decisiones y sus condicionamientos de orden psicológico. Se admitía, eso sí, que el psicoanálisis podía ayudar a explicar el impacto que un hecho histórico podría causar en un individuo, pero ello no explicaría, por supuesto, el hecho mismo en sí. Ni la patología del carácter, más que segura, de Adolf Hitler, ni la neurosis de Iván el Terrible o la de Dovstoievski, vendrían a explicar los problemas históricos que cada una de esas personalidades arrastra tras de sí $^{28}$. Las iluminarían, como mucho.

Correspondía pues a la metodología científico-social el precisar al máximo los desarrollos prácticos de esta premisa, «demostrar que la libre elección o la libre voluntad no es meramente un factor arbitrario, una especie de Deus ex machina que imposibilita cualquier ordenamiento racional de la historia humana, sino que, por el contrario, aquella es susceptible al análisis racional e incluso a la formulación matemática ${ }^{29}$. Certezas de este tipo, ligadas al triunfo del cuantitativismo y las filosofías de tipo estructural, iban a comenzar a disiparse en el seno de la sacudida intelectual que acompañó a los movimientos sociales de 1968, aunque no se impusieran alternativas todavía. Lo que hemos denominado posteriormente la «vuelta del sujeto» arraiga en ese ambiente, $y$ en él ha de insertarse su inseparable fuerza emocional.

Dos décadas después, a finales del siglo XX, aquellas críticas se habían vuelto casi inexistentes, y se apreciaba en cambio como novedad la incursión

27 RABB, Th.K. y Rotberg, R.I. (eds.) (1971), The Family in History. Interdisciplinary Essays, N. York, Harper \& Row.

28 BesAnÇON, A. (1964), «Histoire et psychanalyse», Annales XIX/2, pp. 237-249.

29 Barraclough, G. Historia ... cit., p. 360, citando a L.von Bertalanffy (1962), General Systems, Ann Arbor, Society for General System Research. 
renovada en el campo de la psicología individual, como una fuente reencontrada y legítima para avivar el conocimiento histórico. La reflexión crítica sobre ese tipo nuevo de literatura histórica es también parte de la más reciente exploración biográfica, que muestra un especial interés por los recursos retóricos y el clásico valor ejemplarizante del subgénero.

A mediados de la década de 1970, tras haber dedicado toda su anterior vida profesional a la historia serial, había sido ya nada menos que el maestro Georges Duby, indiscutido árbitro en historia de las mentalidades, quien no tendría empacho en declarar que la biografía era «el género sin duda más difícil», pero también el más ilustrativo, el más aclaratorio (le plus éclairant) de cuantos un historiador se permitiría abordar ${ }^{30}$. Algunos de sus colegas se sorprendieron - $\mathrm{y}$ la mayoría se inquietaron-, por manifestaciones de historiadores de lo social que, como ésta - y de forma tan impensada como inevitable-, suponían un reconocimiento profesional renovado hacia el cultivo, antiguo, de lo concreto y lo particular.

La recuperación actual de la biografía no surge, obviamente, sólo a partir de una serie de giros y elecciones personales de los historiadores o de cambios de gusto en los lectores, ni puede en ningún caso opinarse tal cosa. Porque no es posible minimizar la importancia de la reflexión (que tanto pesa en los análisis actuales, potenciadores de la imagen y el símbolo), sobre cuál sea la entidad cognitiva de otro tipo de fuentes, como es la fotografía por ejemplo. Se ha dicho a este respecto, con razón, que el fotógrafo no sólo fotografía, sino que «biografía», de manera que «la verdadera vida está en una imagen ficticia, no en el cuerpo real» ${ }^{31}$.

Lo mismo cabría decir de la evocación de los recuerdos y su profunda ligazón a los objetos personales, algo que informa la indagación psicoterapéutica por una parte, y que por otra es la trama básica de una denominada historia del presente o historia reciente, en la que una fuente de alimentación importante tiene que ver con el horror del holocausto y el aniquilamiento de los campos nazis. Primo Levi lo expresa con la absoluta y radical sencillez de haber pisado el límite y haberlo rebasado: «Pensad cuánto valor, cuánto significado se encierra aún en las más pequeñas de nuestras costumbres cotidianas, en los cien objetos nuestros que el más humilde mendigo posee: un pañuelo, una carta vieja, la foto de una persona querida. Estas cosas son parte de noso-

30 Duby, G. y Casanova, A. (1974), «Histoire sociale et histoire des mentalités», reprod. en CHARTIER, R. et al. (1987), La sensibilité dans l'histoire, Brionne, Gérard Monfort, p. 51.

31 DeBray, R. (1994), Vida y muerte de la imagen. Historia de la mirada en Occidente, Barcelona, Paidós, p. 24. 
tros, casi como miembros de nuestro cuerpo; y es impensable que nos veamos privados de ellas, en nuestro mundo, sin que inmediatamente encontremos otras que las sustituyan, otros objetos que son nuestros porque custodian y suscitan nuestros recuerdos $»{ }^{32}$.

La biografía se ha reintroducido en las ciencias sociales, en su conjunto y de manera extensa, a raíz de la crisis del objetivismo kantiano y, en consecuencia, como producto del terreno ganado en las ciencias sociales (y también en la historia o historiografía) por todo tipo de subjetivismos filosóficos y sus consiguientes opciones de método que, siendo eminentemente individualistas y fenomenológicas, privilegian lo particular y lo concreto, concediendo lugar principal a la experiencia vivida y los recuerdos. A principios de la década de 1970 era ya perceptible ese rebrote de inspiraciones que no eran nuevas - hay que insistir en ello- - pero sí aparecían, cómo no, renovadas. Se había abierto un espacio para lo particular y contingente, y esta nueva tendencia no pararía de concitar críticas, pero también indisimulados panegíricos ${ }^{33}$, en un magma creciente de cruce de opiniones en cuanto al valor último que, para el historiador, pudiera derivarse de reanudar la exploración sobre claves y efectos de la personalidad individual.

La subjetividad no es ya, de esta manera, simplemente «un escenario interior» más o menos oculto. Sino «una actividad singular de apropiación», incluso si es que ésta opera sin que el sujeto lo sepa-lo que constituye la situación más frecuente-. El sujeto se halla de ese modo sucesivamente ante nuevos problemas, volcado a nuevos retos que le sirven como constante prueba de resistencia. Cada historia individual es de este modo, como sucede en la $\mathrm{mi}$ crohistoria, una cadena de respuestas complejas a las provocaciones de la vida social, en la cual el individuo se ha ido componiendo «una pluralidad de vías a considerar», y en la cual se debate con «un sistema de valores dividido». División del mundo fuera de él, que será, a su vez, «causa de sus vacilaciones, de sus deliberaciones internas y de las comparaciones que hace con otros»».

En conclusión, cada vida particular será «el uso que cada uno hace de sí mismo», el resultado acumulado de «aquello que uno hizo consigo anteriormente» ${ }^{34}$. Los métodos para conocer y descifrar significados a propósito habían sido elaborados poco a poco en las ciencias sociales, acercando a la historia enfoques cualitativos de otras disciplinas, como son las teorías de la identidad,

32 LeVI, P. (2003), Si esto es un hombre, Barcelona, Muchnik editores, p. 40.

33 Por ejemplo, Himmelfarb, G. (1975), «The 'New History'», Commentary LIX, pp. 72-78.

34 Clot, I. (1989), «La otra ilusión biográfica» cit., p. 39. 
las de la acción y de la interacción. Su uso generalizado, con todo, debió esperar considerable tiempo ${ }^{35}$.

Así, las biografías que ahora retornan y andan reincorporándose a la historiografía desde hace unas cuantas décadas, muestran aquella pluralidad de horizontes que viene de la suma de influjos colectivistas — es decir, de los enfoques «fuertes» de las ciencias sociales-y del rescate, por diversas vías, de la importancia de la singularidad, con sus referentes filosóficos propios y sus teorías correlativas ${ }^{36}$. Dos influencias pues, claramente antagónicas, que originan productos historiográficos a veces sensiblemente diferentes, desde la biografía politica individual ${ }^{37}$ hasta la prosopografia ${ }^{38}$, pasando por la sociología histórica y sus derivados ${ }^{39}$, lo que supone cierto tipo de biografías «plurales» como uno de sus capítulos de actividad. En especial, la biografía políti$c a$ revela hasta qué punto, se quiera o no, la historia política (si no toda ella, sí desde luego en todas sus versiones) es todavía deudora de la historia de las ideas políticas, por más que se hayan incorporado a las costumbres y tareas de la comunidad historiográfica variados esfuerzos, de indudable valor, de orden politológico o sociocultural.

Junto a la recomposición de identidades que, en cualquier caso, las biografías colectivas procuran, se dibuja otra vez un uso privilegiado de la biografía individual, más o menos trufada a esta hora de inspiraciones en otro tiempo inapreciables, entre ellas claramente los feminismos ${ }^{40}$, cada día más capaces de conseguir aprecio por parte de públicos tan distintos como amplios. Seguramente tiene ello que ver con la expansión del interés por lo identitario en términos individualizadores que refleja tan claramente el uso microhistórico ${ }^{41}$, también

35 Plummer, K. (1989), Los documentos personales. Introducción a los problemas y la bibliografía del método humanista, Madrid, Siglo XXI.

36 GAgnon, N. (1980), «Données autobiographiques et praxis culturelle», Cahiers Internationaux de Sociologie LXIX, pp. 291-304, y P. THOMPSON (1980): «Des récits de vie á l'analyse du changement social», ibid., pp. 249-268.

37 HANDOURTZEL, R. (1985), «Sur les trajectoires individuelles dans la vie politique», en Problémes et méthodes de la biographie, Sources 4-5, pp. 88-92; C. ARNAUD (1989): «Le retour de la biographie: d'un tabou à l'autre», LE DEBAT 54, pp. 40-47.

38 STONE, L. (1986), «Prosopografía», en El pasado y el presente, México, FCE, pp. 61-94.

39 Laslett, P. (1991), «Biography as Historical Sociology», Theory and Society 20, pp. 501-538.

40 Por ejemplo, S. ALPERn et alii, eds. (1992): The Challenge of Feminist Biography. Writing the Lives of Modern American Women,

41 LeVI, G. (1989), «Les usages de la biographie», Annales. E.S.C. 6, pp. 1325-1336. 
presente en desarrollos concretos de las ciencias sociales, unas y otras en profundo contacto 42 .

Ello exige al historiador emplear las mismas cautelas metodológicas que se usan en la sociología (o en la antropología) a la hora de construir biografias según estos supuestos ${ }^{43}$. Y esas cautelas incluyen previamente el decidir si las preguntas pueden ser respondidas, a través de una «historia de vida» por ejemplo - que tiene un grado alto de reflexividad e impostación subjetiva-, mejor que de otra forma, y no en cambio por cualquier otro procedimiento.

Pero una aproximación existencial a la biografía - que no abunda en la biografía política y ni siquiera en la científica-, y que resulta sin embargo ser hoy la más buscada por su carácter innovador, no significa necesariamente la refutación de la importancia del contexto social en que se desarrolla la existencia de los individuos ${ }^{44}$, y por más que privilegie la organización de la experiencia en torno a una serie de ideas-fuerza, de focos o ideales. De hecho, las relaciones entre el individuo y la sociedad (el yo y los otros, su mirada y el juicio o la valoración de los demás) constituyen un tema persistente en los escritos de inspiración existencialista del siglo XX. (Sartre a propósito de Flaubert, sobre Baudelaire o Genet, por poner un ejemplo). Paradójicamente, resulta ser que prácticamente nadie, en tan amplia manera como los propios científicos, ha solido hacer tanto por romper el cerco de los otros, por tratar de preservar lo que estimarían su yo auténtico frente a la presión exterior, por defender, en fin, lo que Jaspers llamó el «potencial original» ${ }^{45}$.

No podríamos terminar estas páginas sin indicar, last but not least, que la conciencia de la interacción y construcción de la experiencia vivida se hace explícita muy especialmente en las biografías de mujeres hechas, a su vez, por mujeres: «La biografía no es una taxonomía en la que la clasificación del ejemplar deba modificarse según lo último que se descubre; es la historia de una vida por otra vida, un proceso durante el cual ambas evolucionan y cambian» ${ }^{46} \mathrm{El}$ carácter intensamente performativo de la escritura biográfica se manifiesta así: «Si yo no soy la misma persona que hace diez años empezó

42 Bertaux, D. (1981), Biography and Society: The Life History Approach in the Social Sciences, Beverly Hills, Sage.

43 FerrarotTi, F. (1993), «Las biografías como instrumento analítico e interpretativo», en Marinas, J. M. y SANTAMaría, C. (eds.), La historia oral: métodos y experiencias, Madrid, Debate, pp. 129-148.

44 MonK, R. (1994[1990]), Ludwig Wittgenstein, Barcelona, Anagrama.

45 COOPER, D.E. (1990), Existentialism: A Reconstruction, Oxford, Blackwell.

46 LANGer, E. (1983), Josephine Herbst. The Story She Could Never Tell, Boston, Little Brown, p. 13. 
a escribir sobre Kelley - dice una autora que hace biografía—, ¿porqué tenía ella que permanecer inalterable?». Y es que, añade la biógrafa sin el menor escándalo o prejuicio, «como les ocurre a tantas historiadoras de las mujeres, no puedo definir con precisión dónde acaba mi investigación y dónde empieza mi vida privada ${ }^{47}$.

Si decidiéramos que la biografía por excelencia es la biografía existencial, la que concede a los lectores la oportunidad de reorientar sus propias vidas, de hacerlas más ricas y mejores, resultaría quizá que el éxito reciente de la biografía, tanto si asume un valor ejemplar según exigen los patrones clásicos, o tanto si los desprecia o reelabora para abrirse a caminos distintos, tendría siempre que ver con esa capacidad de «sacarnos fuera de nosotros mismos mediante la fuerza de la extrañeza» que le sigue otorgando al género biográfico, por poner un caso, el filósofo americano Richard Rorty 48 .

Cualquier relato biográfico que nos implique afectivamente, claro está, consigue el objetivo emocional y educativo sobre el que Rorty llama la atención, sin que por ello deje de prestar su aporte heurístico, su natural contribución cognitiva. Pero, al menos en lo que respecta a los «relatos de vida» que tienen que ver con la ciencia y el pensamiento, no habría que despreciar - tampoco ahora-aquel antiguo potencial de fomentar la innovación científica y, sobre todo, de aplicación extensa de sus efectos positivos ${ }^{49}$.

Pero también deberíamos considerar que la «cotidianeidad», todo aquello que antes dejaríamos de considerar relevante en el catálogo de nuestros intereses lectores (también en los estrictamente científicos, posiblemente), ha ido recuperando de una manera $\mathrm{u}$ otra, hasta hacerlo bien denso y significativo, aquello que es común, inevitablemente compartido, en nuestras propias vidas: las vidas de todos y a la vez cada uno de nosotros, las vidas de «los más».

$\mathrm{Y}$ ello se hace presente en una radical renovación de los «modelos» ofrecidos, que reflejan aquello que a nuestra vez queremos, y lo que masivamente nos preocupa: "Yo diría que, inexorablemente - ha escrito no hace mucho Félix de Azúa refiriéndose a vidas de literatos-, algunos ídolos como Thomas Mann o André Gide retroceden hacia la oscuridad, en tanto que Henry

47 KISH SKLAR, K. (1995), «El relato de una biógrafa rebelde», Historia y Fuente oral 14, pp. 168 y 166.

48 RoRTY, R. (1980), Philosophy and the Mirror of Nature, Princeton, Princeton University Press, p. 360.

49 SöDERQVIST, T. «Existential Projects...» cit., p. 77: «I believe that one good existential biography of a scientist can better contribute to a remaking of the practices of science than a score of revealing social historical and sociological investigations of science». 
James avanza cada día hacia el centro mismo de la luz». Lo cual solo se explicaría, «por la ejemplar experiencia, el calvario de un hombre que vivió por obligación y en el que muchos han de verse retratados». Pero esto dejaría a su vez al descubierto que «es en verdad significativo que nos interesemos por estos escritores sin vida aparente, estos ciudadanos perfectamente vulgares, porque son ellos los que con lucidez insobornable (y un arte supremo) juzgan y explican la vida, la estúpida vida que todos vivimos. Lo inmenso de sus obras es que en ellas aparece en su más cruda verdad la insignificancia de las vidas normales... y su grandeza» ${ }^{50}$. En efecto, de todo ello trata la biografía actual.

50 DE AzÚA, F. «De los famosos» cit. supra. 